\title{
Knowledge and Attitude of Pharmacists about Biosimilar Medications in Saudi Arabia
}

\author{
Abdullah Khaloofah Alahmari', Ziyad Saeed Almalki', Muhammad Shahid Iqbal ${ }^{1, *}$, Manal Abdullah Alossaimi², Mohammed Zaid Alsaber' \\ Raslan Abdullah Alanazi ${ }^{1}$, Yazeed Mohammed Alruwaili', Saad Nashmi Altheiby ${ }^{1}$, Thekra Omar Bin Salman ${ }^{1}$ \\ 'Department of Clinical Pharmacy, College of Pharmacy, Prince Sattam bin Abdulaziz University, Al-kharj, SAUDI ARABIA. \\ 2Department of Pharmaceutical Chemistry, College of Pharmacy, Prince Sattam bin Abdulaziz University, AI-Kharj, SAUDI ARABIA.
}

\begin{abstract}
Objectives: This study determined knowledge and attitude of pharmacists about biosimilar mdications in Saudi Arabia. Methods: Pharmacists from different areas and regions were approached to participate in this cross-sectional study. Data were collected by a pre-validated and selfadministered research tool using a convenience sampling technique. Analyses and interpretation of the data were done using descriptive and inferential statistics with Statistical Package for Social Sciences (SPSS) version 24.0. Results: A total of 319 pharmacists from different specialties participated in the study. A total of 111 pharmacists were males, and 208 were females. All of the pharmacists had varied expertise. Around $41.4 \%$ of the studied pharmacists were practicing in the community, $34.5 \%$ in hospitals and $24.1 \%$ were in other areas. Conclusion: This study reported the current level of pharmacists' knowledge and attitude about biosimilar
\end{abstract}

medications in Saudi Arabia. Statistically, a significant association was observed between male and female pharmacists regarding the introduction of biosimilar medications in the Saudi Arabian healthcare setup.

Key words: Pharmacists, Biosimilar medications, Knowledge, Attitude, Saudi Arabia.

\section{Correspondence}

\section{Dr. Muhammad Shahid Iqbal}

Department of Clinical Pharmacy, College of Pharmacy, Prince Sattam bin Abdulaziz University, Al-kharj, 11942, SAUDI ARABIA.

Phone no: +966-53-7014420

Email: m.javed@psau.edu.sa

DOI: 10.5530/ijpi.2021.1.23

\section{INTRODUCTION}

Manybiological medications have a competitive version, i.e. manufactured by other producers from other cell lines, they are known as biosimilar medications. They are not identical but have similarities both in the structure and function of biological medications, which is reflected in their efficacy, safety, and clinical characteristics. ${ }^{1-3}$ These novel medicines have nowadays become a considerable part of biological remedies used by numerous experts in the management of various diseases like cancer, rheumatoid arthritis, colitis, diabetes mellitus, Crohn's disease, anemia, immunologic diseases, osteoporosis and other diseases. ${ }^{4-6}$

The European Medicines Agency states that biosimilarity demonstrates a high similarity profile in terms of biological activity, structure, safety, efficacy and immunogenicity to the original medication. ${ }^{7}$ However, biosimilar medications are complex proteins and as a result, these medications will never be an identical duplicate of the original drug because of their high molecular weight, their nature is heterogeneous and because of batch-to-batch complexity and variability. ${ }^{8}$ Biosimilar drugs are obtainable at more reasonable costs. These medications may results in price reductions for reference biological medicinal products and so open up the market to competition. Nevertheless, their market is presently limited and is inconstant among different countries. Many factors may affect the biosimilar market acceptance, such as reimbursement and pricing, incentives, or prescription rules applied at a national level. Moreover, originator companies develop a variety of tactics to compete with biosimilar medications. This emphasizes the need for governments to set up a clear biosimilar policy.-14

Compared to generic medications, biosimilar medications are more complex and need a comprehensive investigation to get marketing approval, including both preclinical and clinical Phase 1 and Phase
3 studies. The regulatory framework implemented to biosimilar medications is well-defined by the Food and Drug Administration and the European Medicines Agency. ${ }^{15-19}$ Currently, not only prescribers but also other healthcare specialists are involved in the distribution, application and usage of biosimilar medications. Stevenson et al. believed that pharmacists could play a significant role in supervising biosimilar medications' introduction into healthcare systems. ${ }^{20}$ Moreover, Beck et al. reported that pharmacists could play an essential role in supporting biosimilar medications by providing appropriate information, promoting acceptance among patients and the health community and warranting their suitable use. ${ }^{21}$ This study aimed to identify pharmacists' knowledge and attitude towards biosimilar medications in Saudi Arabia.

\section{MATERIALS AND METHODS}

\section{Study participants, study instrument and sampling technique}

The study participants were pharmacists practicing in various specialties at various institutes. This study used a self-developed and validated research tool. The study tool was developed after an extensive literature review and consultations within the field. There were three parts of the study tool, i.e., a) demographic characteristics of the study participants, b) knowledge questions, and c) attitude questions. The convenience sampling technique was used to obtain the appropriate sample size.

\section{Study type and data collection}

This was a cross-sectional study conducted in June-August 2019 where various pharmacists were approached to take part in the study. 


\section{Inclusion and exclusion criteria}

For inclusion criteria, only those were included who were registered pharmacists and who signed the consent form. For exclusion criteria, pharmacy technicians, not fully-registered pharmacists, and those who refused to sign the consent forms were excluded from the study.

\section{Statistical analyses}

Data compilation, analyses and interpretations were carried out using Statistical Package for Social Science (SPSS) version 24.0. For the continuous variables, standard deviations (SD) and means were determined, whereas for categorical variables, the percentages with frequencies were determined. Spearman correlation rank test was used to determine the correlation among male and female pharmacists to assess their knowledge and attitude about biosimilar medications in Saudi Arabia. A $p$-value of $<0.05$ was considered statistically significant.

\section{RESULTS}

A total of 319 pharmacists participated in the study. The participated pharmacists were from various regions of the country with different specialties. A total of $34.8 \%$ were females and $65.2 \%$ were male participants. All of the study participants were practicing in various specialties i.e. 132 as community pharmacists, 109 as hospital pharmacists and 78 in miscellaneous settings. The results are presented in Figure 1.

Regarding pharmacists' knowledge about biosimilar medications, the majority of pharmacists answered correctly, but still, some pharmacists showed poor knowledge. For example the question of 'Biosimilar is structurally identical to its reference medicinal product' was answered correctly by $69.59 \%$ of the pharmacists. The results of knowledge about biosimilar medications among pharmacists are shown in Table 1.

Generally, the pharmacists showed a positive attitude toward biosimilar medications. About $60.50 \%$ of the pharmacists had a positive attitude regarding the interchangeability of routine medications with biosimilar

Table 1: Knowledge about biosimilar medications $\mathbf{N}(\%)$.

\begin{tabular}{|c|c|c|}
\hline Questions & Yes & No \\
\hline $\begin{array}{l}\text { Biosimilar is structurally identical to its reference } \\
\text { medicinal product. }\end{array}$ & $\begin{array}{c}222 \\
(69.59)\end{array}$ & $97(30.40)$ \\
\hline $\begin{array}{l}\text { Biosimilar is similar to a reference medicinal } \\
\text { product that has gone off-patent. }\end{array}$ & $\begin{array}{c}211 \\
(66.14)\end{array}$ & $\begin{array}{c}108 \\
(33.85)\end{array}$ \\
\hline $\begin{array}{l}\text { Biosimilar has no meaningful differences from a } \\
\text { reference medicinal product in terms of quality. }\end{array}$ & $\begin{array}{c}187 \\
(58.62)\end{array}$ & $\begin{array}{c}132 \\
(41.37)\end{array}$ \\
\hline $\begin{array}{l}\text { Biosimilar has no meaningful differences from a } \\
\text { reference medicinal product in terms of safety. }\end{array}$ & $\begin{array}{c}208 \\
(65.20)\end{array}$ & $\begin{array}{c}111 \\
(34.79)\end{array}$ \\
\hline $\begin{array}{l}\text { Biosimilar has no meaningful differences from a } \\
\text { reference medicinal product in terms of efficacy. }\end{array}$ & $\begin{array}{c}208 \\
(65.20)\end{array}$ & $\begin{array}{c}111 \\
(34.79)\end{array}$ \\
\hline $\begin{array}{c}\text { Biosimilar has the same dosage and route of } \\
\text { administration compared to its reference medicinal } \\
\text { product. }\end{array}$ & $\begin{array}{c}199 \\
(62.38)\end{array}$ & $\begin{array}{c}120 \\
(37.61)\end{array}$ \\
\hline $\begin{array}{l}\text { Biosimilar is a drug for which marketing } \\
\text { authorization is granted on the sole investigation of } \\
\text { pharmacokinetic bioequivalence with its reference } \\
\text { medicinal product. }\end{array}$ & $\begin{array}{c}266 \\
(83.38)\end{array}$ & $53(16.61)$ \\
\hline $\begin{array}{l}\text { Biosimilar requires more comprehensive data in } \\
\text { terms of preclinical and clinical studies as compared } \\
\text { to generic drugs. }\end{array}$ & $\begin{array}{c}287 \\
(89.96)\end{array}$ & $32(10.03)$ \\
\hline $\begin{array}{c}\text { Biosimilars don't require preclinical and clinical } \\
\text { studies. }\end{array}$ & $44(13.79)$ & $\begin{array}{c}275 \\
(86.20)\end{array}$ \\
\hline
\end{tabular}

medications. Additionally, $48.58 \%$ also believed that biosimilar medication substitution should only be done after consultation with the prescriber. Table 2 shows the pharmacists' attitude towards biosimilar medications.

Table 3 demonstrates correlative differences among the male and female pharmacists regarding their knowledge and attitude about biosimilar medications. Statistically, non-significant differences $(p>0.05)$ were observed except for the question "biosimilar medications don't require preclinical and clinical studies.”

\section{DISCUSSION}

The current study aimed to identify the knowledge and attitude of pharmacists regarding biosimilar formulations in Saudi Arabia. This study observed that around $58.62 \%$ of the pharmacists responded that biosimilar medications had no meaningful differences from their reference medicinal products in terms of quality and 132 pharmacists (41.37\%) responded that biosimilar medications had significant differences from their reference medicinal products in terms of quality. These results are rational as biosimilar formulations are a relatively new therapy approach whereby numerous healthcare professionals are not thoroughly familiar with. ${ }^{19-23}$ Our study results are in contrast with Iga Pawłowska et al. and Joan O'Callaghan et al. who reported that the majority of the pharmacists in their studies expressed greater familiarity with biosimilar medications and their uses. ${ }^{8,24}$ Moreover, the findings from many other similar studies from different parts of the world like New Zealand, the USA, Ireland, and the UK suggest that the majority of the healthcare professionals, especially pharmacists had adequate knowledge about biosimilar medications and their benefits, but still there are several knowledge and attitude gaps regarding biosimilar medications. ${ }^{6,82,26}$ Similarly, another study done by Aladul $\mathrm{M}$ et al. reported that pharmacists had an appropriate knowledge about biosimilar medications. They also reported that pharmacists' knowledge was way better than the knowledge of other health care professionals regarding biosimilar medication uses and benefits. ${ }^{27}$

More academic knowledge and a positive attitude are required from pharmacists and other healthcare professionals to increase biosimilar medications' familiarity and dispense them appropriately. ${ }^{24-27}$ Besides, as per the results of our study, pharmacists need to improve further and update their current knowledge regarding biosimilar medications in Saudi Arabia. Another solution that might work could be that the current pharmacy curriculum is modified and updated regularly to keep up with the new trends and the latest advancements in the recent treatment options like biosimilar medications among patients experiencing chronic diseases.

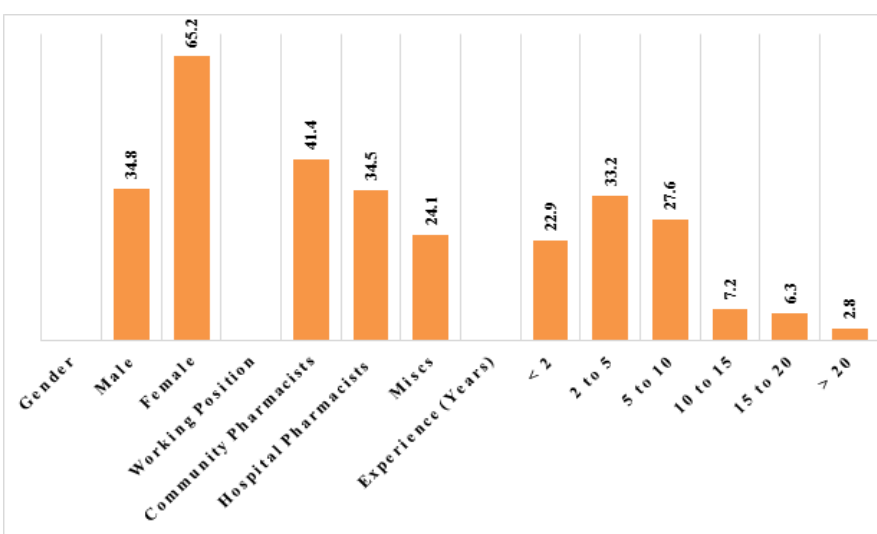

Figure 1: Demographic characteristics of the study participants (\%). 
Table 2: Pharmacists' attitude towards biosimilar medications N (\%).

\begin{tabular}{|c|c|c|c|}
\hline Questions & Agree & Neutral & Disagree \\
\hline $\begin{array}{l}\text { Interchangeability of medicines with } \\
\text { biosimilars is beneficial. }\end{array}$ & $\begin{array}{c}193 \\
(60.50)\end{array}$ & $\begin{array}{c}100 \\
(31.34)\end{array}$ & 5) \\
\hline $\begin{array}{l}\text { Do you favor changing a biological } \\
\text { product with a biosimilar? }\end{array}$ & $\begin{array}{c}120 \\
(37.61)\end{array}$ & $\begin{array}{c}164 \\
(51.41)\end{array}$ & 35 \\
\hline $\begin{array}{l}\text { Substituting a biologic product with } \\
\text { biosimilar without consulting the } \\
\text { prescriber is adequate. }\end{array}$ & $\begin{array}{c}64 \\
(20.06)\end{array}$ & $\begin{array}{c}100 \\
(31.34)\end{array}$ & $\begin{array}{c}155 \\
(48.58)\end{array}$ \\
\hline $\begin{array}{l}\text { Purchasing and dispensing biosimilars by } \\
\text { trade names is acceptable. }\end{array}$ & $\begin{array}{c}152 \\
(47.64)\end{array}$ & $\begin{array}{c}100 \\
(31.34)\end{array}$ & $67(21.00)$ \\
\hline $\begin{array}{c}\text { Do you support biosimilars usage in } \\
\text { Saudi Arabia? }\end{array}$ & $\begin{array}{c}260 \\
(81.50)\end{array}$ & $\begin{array}{c}44 \\
(13.79)\end{array}$ & $15(4.70)$ \\
\hline
\end{tabular}

Table 3: Differences of knowledge and attitude among male and female pharmacists regarding biosimilar medications.

\begin{tabular}{|cc}
\hline \multicolumn{1}{c}{ Questions } & $p$-Value \\
$\begin{array}{c}\text { Biosimilar medications require more comprehensive data } \\
\text { regarding preclinical and clinical studies than generic drugs. } \\
\text { Substituting a biologic product with biosimilar without } \\
\text { consulting the prescriber. }\end{array}$ & 0.125 \\
$\quad \begin{array}{c}\text { Biosimilar medications don't require preclinical and clinical } \\
\text { studies }\end{array}$ & 0.093 \\
Introducing biosimilars in Saudi Arabia at a broader level. & 0.557 \\
* Correlation was significant at $<0.05$ &
\end{tabular}

Our study findings also deduce that most study pharmacists i.e., 155 (48.58\%) opposed that biologic products should be replaced with biosimilar medications without getting consent from the prescribers. However, $31.34 \%$ were neutral in that, and $20.06 \%$ of the participants were comfortable and agreed to change a biologic product prescribed by a prescriber with a biosimilar medication without informing the prescriber. These results were similar to some other results, which reported that most pharmacists in their study felt that the substitution led by pharmacists (without informing the prescribers) was not appropriate. ${ }^{24}$ Fortunately, Food and Drug Administration has finalized its guidelines about biosimilar medications interchangeability, which will ultimately allow pharmacists to routinely dispense therapeutically equivalent and cheaper alternatives than the current routine medications. $^{28}$

On the other hand, 152 (47.64\%) of the pharmacists showed a positive attitude about purchasing and dispense biosimilars by trade names, whereas 67 (21\%) felt it inappropriate, i.e., negative attitude towards positively towards the buy and dispense biosimilars by trade names. The majority of the pharmacists i.e., $260(81.50 \%)$ were in strong favor of introducing biosimilars in Saudi Arabia and just 15 (4.70\%) of the studied pharmacists opposed this idea. These findings were rational because the FDA's approval of biosimilar products increases the number of medication options that are already available at lower costs in various developed countries.

In terms of the correlations or differences between the two genders (male and female) about knowledge and attitude towards biosimilar medications and their benefits, overall, statistically, a non-significant association ( $p$-value $>0.05$ ) was observed. On the other hand, a statistically significant association $(p$-value $<0.05)$ was observed among them in terms of biosimilar medications preclinical and clinical evidence before their approval. This finding indicated that both of the genders had different opinions and familiarity levels regarding biosimilar medications' safety data in terms of preclinical and clinical evidence.

\section{CONCLUSION}

Overall, the study concluded an excellent knowledge and a positive attitude about biosimilar medications among pharmacists in Saudi Arabia. Besides, more awareness by decreasing the information gap is required for safer dispensing of biosimilar medications to the patients. Furthermore, it is also essential to update pharmacy students' curricula regarding the use of biosimilar medicines to ensure their safety and efficacy.

\section{ACKNOWLEDGEMENT}

The authors would like to thank the Deanship of Scientific Research at Prince Sattam bin Abdulaziz University, Alkharj, Saudi Arabia, to support this publication.

\section{REFERENCES}

1. Jarrett S, Dingermann T. Biosimilars are here: A hospital pharmacist's guide to educating health care professionals on biosimilars. Hosp Pharm. 2015;50(10):884-93.

2. Tsiftsoglou AS, Ruiz S, Schneider CK. Development and regulation of biosimilars: Current status and future challenges. Bio Drugs. 2013;27(3):203-11.

3. Kurki P, Aerts LV, Wolff-Holz E, Giezen T, Skibeli V, Weise M. Interchangeability of biosimilars: A European perspective. Bio Drugs. 2017;31(2):83-91.

4. Sieczkowska-Golub J, Jarzebicka D, Oracz G, Kierkus J. Biosimilars in paediatric infammatory bowel disease. World J Gastroenterol. 2018;24(35):4021-7.

5. Jordan JB, Christl L. FDA Biosimilar Action Plan: Could improving pharmacovigilance of biologics improve patient and physician confidence in biosimilars?. Expert Opin Drug Saf. 2020;19(3):229-32.

6. Cohen H, Beydoun D, Chien D, Lessor T, McCabe D, Muenzberg M, et al. Awareness, knowledge, and perceptions of biosimilars among specialty physicians. Adv Ther. 2016;33(12):2160-72

7. Markus R, Liu J, Ramchandani M, Landa D, Born T, Kaur P. Developing the totality of evidence for biosimilars: Regulatory considerations and building confidence for the healthcare community. Bio Drugs. 2017;31(3):175-87.

8. O'Callaghan J, Bermingham M, Leonard M, Hallinan F, Morris JM, Moore U, et al. Assessing awareness and attitudes of healthcare professionals on the use of biosimilar medicines: A survey of physicians and pharmacists in Ireland. Regul Toxicol Pharmacol. 2017;88:252-61.

9. Declerck PJ, Simoens S. A European perspective on the market accessibility of biosimilars. Biosimilars. 2012;2:33-40.

10. Bocquet F, Paubel P, Fusier F, Cordonnier AL, Sinegre M, LePen C. Biosimilar versus patented erythropoietins: learning from 5 years of European and Japanese experience. Appl Health Econ Health Policy. 2015;13(1):47-59.

11. Bocquet F, Loubiere A, Fusier I, Cordonnier AL, Paubel P. Competition between biosimilars and patented biologics: Learning from European and Japanese experience. Pharmacoeconomics. 2016;34 (11):1173-86.

12. Dylst $P$, Vulto $A$, Simoens $S$. Barriers to the uptake of biosimilars and possible solutions: A Belgian case study. Pharmacoeconomics. 2014;32(7):681-91.

13. Mestre-Ferrandiz J, Towse A, Berdud M. Biosimilars: How can payers get longterm savings?. Pharmacoeconomics. 2016;34(6):609-16.

14. Bocquet F, Paubel P, Fusier I, Cordonnier AL, Pen CL, Sinegre M. Biosimilar granulocyte colony-stimulating factor uptakes in the EU-5 markets: A descriptive analysis. Appl Health Econ Health Policy. 2014;12(3):315-26.

15. Lucio SD, Stevenson JG, Hoffman JM. Biosimilars: Implications for healthsystem pharmacists. Am J Health-Syst Pharm AJHP Off J Am Soc Health-Syst Pharm. 2013;70(22):2004-17.

16. Kurki P, Ekman N. Biosimilar regulation in the EU. Expert Rev Clin Pharmacol. 2015;8(5):649-59.

17. Calvo B, Zuñiga L. The US approach to biosimilars. Biodrugs. 2012;26(6):357-61.

18. Committee for Medicinal Products for Human use of European Medicines Agency (EMA). Guideline on similar biological medicinal products containing biotechnology-derived proteins as active substance: Quality issues (revision 1). 2014.

19. European Medicines Agency (EMA). Guideline on similar biological medicinal products containing monoclonal antibodies: Non-clinical and clinical issues. 2012.

20. Stevenson JG, Popovian R, Jacobs I, Hurst S, Shane LG. Biosimilars: Practical considerations for pharmacists. Ann Pharmacother. 2017;51(7):590-602.

21. Beck M, Michel B, Rybarczyk-Vigouret M, Levêque D, Sordet C, Sibilia J, et al. Knowledge, behaviors and practices of community and hospital pharmacists 
towards biosimilar medicines: Results of a French web-based survey. Taylor and Francis. 2016;9(2):384-91.

22. Pawłowska I, Pawłowski L, Krzyżaniak N, Kocić I. Perspectives of Hospital Pharmacists Towards Biosimilar Medicines: A Survey of Polish Pharmacy Practice in General Hospitals. Bio Drugs. 2019;33(2):183-91.

23. Almalki ZS, lqbal MS, Alossaimi MA, Lasaf AM, Almawash BA, Aldossary FH, et al. Physicians' Knowledge and Awareness about Biosimilars in Saudi Arabia: What is Imperative to Know ?. J Young Pharm. 2020;12(3):280-4.

24. Pawlowska I, Pawłowski L, Krzyżaniak N, Kocić I. Perspectives of Hospital Pharmacists Towards Biosimilar Medicines: A Survey of Polish Pharmacy Practice in General Hospitals. Bio Drugs. 2019;33(2):183-91.
25. Chapman SR, Fitzpatrick RW, Aladul MI. Knowledge, attitude and practice of healthcare professionals towards infliximab and insulin glargine biosimilars: Result of a UK web-based survey. BMJ Open. 2017;7(6):e016730.

26. Hemmington A, Dalbeth N, Jarrett $P$, Fraser AG, Broom R, Browett $P$, et al Medical specialists' attitudes to prescribing biosimilars. Pharmacoepidemiol Drug Saf. 2017;26(5):570-7.

27. Chapman SR, Fitzapatrick R, Aladul M. Differences in UK healthcare professionals" knowledge, attitude and practice towards infliximab and insulin glargine biosimilars. Int J Pharm Pract. $2019 ; 27(2): 214-7$.

28. Hobbs AL, Crawford JP. Biosimilars and implications for pharmacy practice: Ready or not, here they come!. Pharm Pract. 2019;17(3):1659-65.

Article History: Submission Date : 29-04-2020; Revised Date : 11-10-2020; Acceptance Date : 15-02-2021

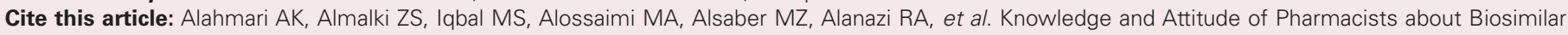
Medications in Saudi Arabia. Int. J. Pharm. Investigation. 2021;11(1):123-6. 